\title{
Sodium-Glucose Co-transporter 2 Inhibitors in the Failing Heart: a Growing Potential
}

\author{
Dulce Brito ${ }^{1,2}$ - Paulo Bettencourt ${ }^{3,4}$. Davide Carvalho ${ }^{4,5,6}$ - Jorge Ferreira ${ }^{7}$. Ricardo Fontes-Carvalho ${ }^{8,9}$. \\ Fátima Franco ${ }^{10}$. Brenda Moura ${ }^{4,11,12}$. José Carlos Silva-Cardoso 4,12,13 . Rachel Tavares de Melo ${ }^{14}$. \\ Cândida Fonseca ${ }^{15,16}$
}

Published online: 30 April 2020

(C) The Author(s) 2020

\begin{abstract}
Sodium-glucose co-transporter 2 inhibitors (SGLT2i) are a new drug class designed to treat patients with type 2 diabetes (T2D). However, cardiovascular outcome trials showed that SGLT2i also offer protection against heart failure (HF)-related events and cardiovascular mortality. These benefits appear to be independent of glycaemic control and have recently been demonstrated in the HF population with reduced ejection fraction (HFrEF), with or without T2D. This comprehensive, evidence-based review focuses on the published studies concerning HF outcomes with SGLT2i, discussing issues that may underlie the different results, along with the impact of these new drugs in clinical practice. The potential translational mechanisms behind SGLT2i cardio-renal benefits and the information that ongoing studies may add to the already existing body of evidence are also reviewed. Finally, we focus on practical management issues regarding SGLT2 $\mathrm{i}$ use in association with other T2D and HFrEF common pharmacological therapies. Safety considerations are also highlighted. Considering the paradigm shift in T2D management, from a focus on glycaemic control to a broader approach on cardiovascular protection and event reduction, including the potential for wide SGLT2 $\mathrm{i}$ implementation in HF patients, with or without T2D, we are facing a promising time for major changes in the global management of cardiovascular disease.
\end{abstract}

Keywords SGLT2i $\cdot$ Diabetes $\cdot$ Heart failure $\cdot$ Cardiovascular risk $\cdot$ Cardiovascular outcomes trials

Electronic supplementary material The online version of this article (https://doi.org/10.1007/s10557-020-06973-3) contains supplementary material, which is available to authorized users.

Dulce Brito

dulce.brito@chln.min-saude.pt

1 Department of Cardiology, Centro Hospitalar Universitário Lisboa Norte, Av. Prof. Egas Moniz, 1649-035 Lisboa, Portugal

2 CCUL, Faculdade de Medicina, Universidade de Lisboa, Av. Prof. Egas Moniz, 1649-035 Lisboa, Portugal

3 Department of Internal Medicine, Hospital CUF Porto, Porto, Portugal

4 Faculdade de Medicina, Universidade do Porto, Porto, Portugal

5 Department of Endocrinology, Diabetes and Metabolism, Centro Hospitalar, Universitário de São João, Porto, Portugal

6 Instituto de Investigação e Inovação em Saúde, Universidade do Porto, Porto, Portugal

7 Department of Cardiology, Hospital de Santa Cruz, Centro Hospitalar de Lisboa Ocidental, Lisbon, Portugal
8 Department of Cardiology, Centro Hospitalar Vila Nova de Gaia/Espinho, Espinho, Portugal

9 Department of Surgery and Physiology, Cardiovascular Investigation Unit, Faculdade de Medicina, Universidade do Porto, Porto, Portugal

10 Department of Cardiology, Centro Hospitalar e Universitário de Coimbra, Coimbra, Portugal

11 Department of Cardiology, Hospital das Forças Armadas-Pólo do Porto, Porto, Portugal

12 CINTESIS-Cardiocare, Center for Health Technology and Services Research, Porto, Portugal

13 Department of Cardiology, Centro Hospitalar Universitário de São João, Porto, Portugal

14 Medical Department, Boehringer Ingelheim, Lisboa, Portugal

15 Heart Failure Clinic, Hospital São Francisco Xavier, Centro Hospitalar de Lisboa Ocidental, Lisboa, Portugal

16 NOVA Medical School, Faculdade de Ciências Médicas, Universidade Nova de Lisboa, Lisboa, Portugal 


\section{Diabetes and Heart Failure}

Type 2 diabetes (T2D) and heart failure (HF) are common and often coexisting conditions, with a harmful relationship. HF affects at least 26 million people worldwide, but projections regarding rising prevalence for the next decades are alarming, namely due to an ageing population and to the expected increase in $\mathrm{HF}$ with preserved ejection fraction (HFpEF) [1-5]. Currently, despite advances in HF treatment, mortality can reach $50 \%$ at five years, exceeding that observed in most common malignant neoplasms [6, 7]. Hospitalizations contribute to the high morbidity in $\mathrm{HF}$ and account for most of its costs, which are likely to rise dramatically $[3,4,8]$.

The prevalence of T2D has nearly doubled since 1980 and is expected to affect nearly 580 million individuals worldwide in 10 years, and 700 million by $2045[9,10]$. T2D is a major risk factor for the development of cardiovascular disease (CVD), its main cause of morbidity and mortality [11, 12].

The relationship between T2D and HF has been well established since the Framingham study, which reported a 2and 5-fold higher risk of HF in men and women with T2D, respectively, compared with individuals without T2D [13]. More recently, the Reykjavik study described a $12 \%$ prevalence of $\mathrm{HF}$ in the T2D population vs. $3 \%$ in individuals without T2D [14].

T2D is associated with cardiac structural changes including increased interstitial fibrosis, left ventricular hypertrophy, endothelial dysfunction, microangiopathic processes and inflammation, factors that confer a higher risk for developing HF with or without a reduced ejection fraction (rEF) [15]. T2D adversely affects outcomes amongst patients with HF, has a substantial influence on the costs of managing HF patients, extends hospital stay and worsens prognosis $[4,16]$. On the other hand, HF increases the risk of fatal and non-fatal cardiovascular (CV) events in T2D patients [17].

Sodium-glucose co-transporter 2 inhibitors (SGLT2i) have emerged as a new class of drugs designed to treat patients with T2D, but have also been shown to be protective against HF-related events and CV mortality. Herein, we present a comprehensive, evidence-based overview concerning the use of SGLT2i in patients with or without $\mathrm{T} 2 \mathrm{D}$ at risk for $\mathrm{CV}$ events, focusing on $\mathrm{HF}$ outcomes. Additionally, we perform a critical analysis of the SGLT2i cardiovascular outcome trials (CVOTs) and discuss the SGLT2i possible translational mechanisms behind the clinical outcomes, with an overview of the ongoing SGLT2i functional capacity, mechanistic and HF outcomes trials. Finally, we present a summary of practical considerations regarding the co-administration of SGLT2 $i$ and common therapies used in T2D and HFrEF, as well as management of safety issues, based on expert opinion and current recommendations.
Improving Prognosis: the Clinical Research Arena

\section{SGLT2i Cardiovascular Outcome Trials in T2D Patients}

Due to concerns for possible adverse CV outcomes with antidiabetic agents, both the Food and Drug Administration (FDA) and the European Medicines Agency require that all new glucose-lowering drugs demonstrate $\mathrm{CV}$ safety in $\mathrm{T} 2 \mathrm{D}$ patients. This is now tested in CVOTs that analyse drug safety in terms of MACE (major adverse cardiovascular events), which include CV death, non-fatal myocardial infarction (MI) and non-fatal stroke (3-point MACE). Surprisingly, HF outcomes, which can be precipitated by some antidiabetic drugs [18], are not included as a mandatory component of composite endpoints [19].

A paradigm shift in $\mathrm{T} 2 \mathrm{D}$ management emerged when CVOTs with SGLT2i [20-22] demonstrated that these drugs are not only safe in terms of 3-point MACE but may also be beneficial in HF-related and renal events, regardless of the presence of atherosclerotic CVD (ASCVD) or HF at baseline.

\section{The EMPA-REG OUTCOME Trial}

The EMPA-REG OUTCOME trial analysed the outcomes of the SGLT2i empagliflozin vs. placebo in patients with T2D and established CVD at baseline, and demonstrated the superiority of empagliflozin in reducing the risk of 3-point MACE, with significant reductions in CV death, all-cause death and in hospitalization for HF (HHF). Observed benefits were related to a decrease in incident $\mathrm{HF}$ events rather than to prevention of ischemic CV events [20]. These unexpected results led empagliflozin to become the first glucose-lowering drug approved for $\mathrm{CV}$ death protection in T2D patients.

Post hoc analyses of the EMPA-REG OUTCOME trial revealed that besides the higher incident rates of HHF, CV death and all-cause mortality in patients with HF at baseline compared with patients without HF, the risk reductions of these outcomes with empagliflozin were consistent in both subgroups (hazard ratio (HR): $0.67,95 \%$ confidence interval (CI) 0.47-0.97 in patients with HF burden (defined as HF at baseline, HHF or incident HF without hospitalization during the trial); HR $0.63,95 \%$ CI $0.48-0.84$ in patients without HF burden) [23]. The observed benefit with empagliflozin extends to the two causes of cardiac death in HF: sudden death and pump failure [24].

\section{The CANVAS Program and the DECLARE-TIMI 58 Trial}

The CANVAS program [21], which included the CANVAS and CANVAS-R (renal) studies, assessed the CV safety and efficacy of canagliflozin in patients with T2DM and established CVD or at least two risk factors for CVD. The 


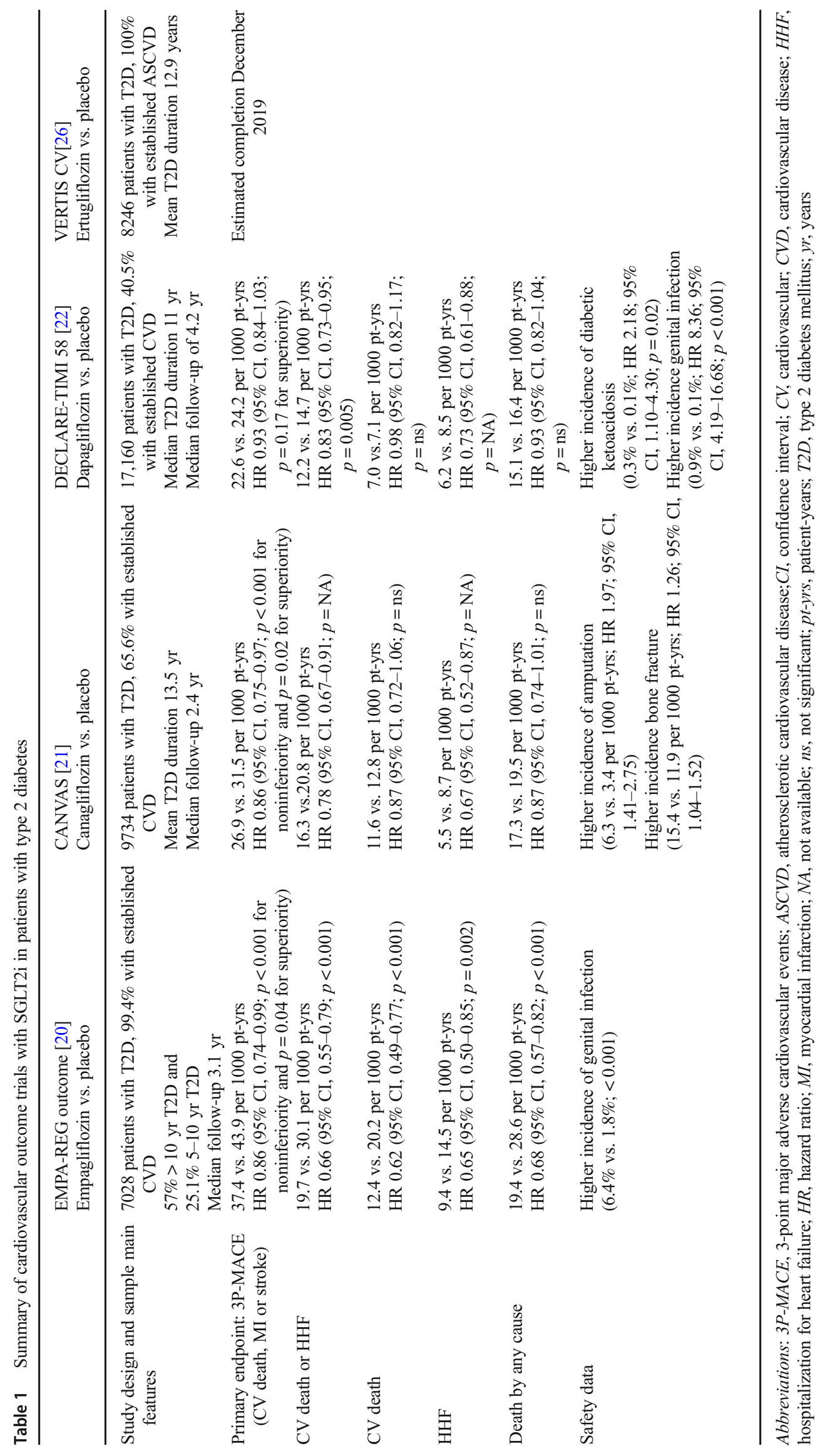


DECLARE-TIMI 58 trial [25] compared dapagliflozin vs. placebo in patients with T2DM with either established ASCVD or multiple risk factors for ASCVD. These trials showed that both SGLT2i also reduced the composite endpoint of $\mathrm{CV}$ death and HHF in T2D patients, with similar results observed with dapagliflozin for patients with and without $\mathrm{HF}$ at baseline [22]. The results for both trials were driven by a reduction in HHF, with no significant reduction in $\mathrm{CV}$ death alone.

Table 1 presents a summary of the CVOTs with SGLT2i. These CVOTs have different designs and inclusion criteria, and therefore are difficult to compare; additionally, the definition of $\mathrm{CV}$ risk is variable across studies, and there is no information regarding baseline LV ejection fraction (LVEF).

\section{Meta-analyses}

A question that remains unresolved is whether the effects are consistent across the SGLT2i class, or whether pharmacologic differences between the drugs may translate into differences in clinical efficacy and safety outcomes.

Two meta-analyses on SGLT2i CVOTs have been recently published, aiming to better estimate the class effect of these drugs on CV outcomes [27, 28]. The most recent metaanalysis showed a consistent class effect of SGLT2i in reducing HHF in patients with or without baseline CVD, as well as a consistent effect on preventing the progression of renal disease [27].

Overall, SGLT2i reduced the risk of MI by $11 \%$ and the risk of CV death by $16 \%$, although significant heterogeneity in $\mathrm{CV}$ death was observed between trials. Similarly, all-cause mortality was reduced by $15 \%$, again with significant heterogeneity. When only patients with ASCVD were compared within trials (excluding patients with multiple $\mathrm{CV}$ risk factors in the CANVAS and DECLARE-TIMI 58 trials), empagliflozin was the only that showed significant reductions on CV death and all-cause mortality. Similarly, an increased risk in amputations and fractures was only noted with canagliflozin [27].

It is possible that either pharmacologic differences within the class, or differences in the baseline risk within the study populations, may be responsible for the observed heterogeneity in mortality outcomes. The consistently higher event rates in the placebo group in EMPA-REG (compared with the placebo arms in CANVAS and DECLARE-TIMI 58) reflect a higher risk population in the former (also when comparing the ASCVD groups only), which might account for the differences observed between trials.

The estimated glomerular filtration rate (eGFR) cut-off for EMPA-REG was less restrictive, thus allowing for patients with more severe renal dysfunction to be included in the trial. The percentage of patients with eGFR $<60 \mathrm{~mL} / \mathrm{min}$ was $25.9 \%$ in EMPA-REG compared with $20.1 \%$ in CANVAS and $7.4 \%$ in DECLARE-TIMI 58. Nonetheless, in a subanalysis conducted to determine the impact of eGFR on $\mathrm{CV}$ death in EMPA-REG, a consistent effect on CV mortality was observed, independent of baseline eGFR [20, 29, 30].

Furthermore, the recent CREDENCE trial tested canagliflozin vs. placebo in $4200 \mathrm{~T} 2 \mathrm{D}$ patients with nephropathy, an eGFR of 30 to $<90 \mathrm{~mL} / \mathrm{min}$ and albuminuria [31]. Over $50 \%$ of the population had established CVD, and $14.8 \%$ had HF at baseline. During a median follow-up of 2.62 years, canagliflozin did not significantly reduce $\mathrm{CV}$ death alone, despite a nominally non-significant $p$ value (HR $0.78,95 \%$ CI $0.61-1.00, p=0.05)$, or all-cause death ((HR $0.83,95 \% \mathrm{CI}$ $0.68-1.02, p=$ not available (NA)), but showed a pronounced reduction in HHF (HR 0.61, 95\% CI 0.47-0.80, $p<0.001$ ).

In aggregate, these findings suggest that in patients with greater renal dysfunction, SGLT2i confer even higher reductions in HHF, as also suggested by the meta-analysis results [27]. However, the degree of renal dysfunction or presence of established CVD does not appear to fully explain the observed heterogeneity in terms of mortality amongst the three published SGLT2i CVOTs.

Based on this heterogeneity, the 2019 European Society of Cardiology (ESC) Guidelines [32] on diabetes, pre-diabetes and CVD, developed in collaboration with the European Association for the Study of Diabetes (EASD), has given empagliflozin a class IB recommendation to reduce the risk of death in patients with T2D and CVD. In addition, empagliflozin, dapagliflozin and canagliflozin are recommended in patients with T2D and CVD or at very high/high $\mathrm{CV}$ risk, to reduce $\mathrm{CV}$ events, as first-line antidiabetic therapy in naive patients, not previously treated with metformin [32]. This recommendation is criticized, namely by the convincing beneficial effects (HbAlc 6.5-7.5\%) (glycated haemoglobin) of early combination therapy [33].

A CVOT with the SGLT2i ertugliflozin [26] is currently underway, with results expected in the near future (Table 1).

\section{SGLT2i Effects on HF Outcomes in T2D Patients}

Additional subanalyses of the three abovementioned CVOTs [20-22] have been published, revealing further data concerning SGLT2i effects on HF outcomes in patients with T2D.

An analysis of the CANVAS program showed that canagliflozin reduced the overall risk of HF events in patients with T2D and high CV risk, with no clear difference in effects on HFrEF vs. HFpEF events [34].

A recent analysis of the DECLARE-TIMI 58 trial investigated the efficacy of dapagliflozin in T2D patients considering baseline HF status [25]. In patients with T2D and baseline HFrEF, dapagliflozin reduced HHF, CV death and all-cause mortality, whereas in patients with T2D without baseline HFrEF, the only reduction observed was in HHF [25]. 


\section{SGLT2i HF-Dedicated Outcomes Trials in Patients with or without T2D}

More recently, the DAPA-HF trial results were published [35]. The trial included 4744 HFrEF patients with our without T2D followed over a median of 18.2 months. It was demonstrated that dapagliflozin $10 \mathrm{mg}$ daily significantly reduced the primary composite endpoint of worsening HF (including HHF or urgent $\mathrm{HF}$ visits) and $\mathrm{CV}$ death in a population highly treated with background disease-modifying HF therapies (HR 0.74, 95\% CI $0.65-0.85, p=0.001$ ), either in patients with (HR $0.75,95 \%$ CI $0.63-0.90, p=\mathrm{NA}$ ) or without diabetes (HR $0.73,95 \%$ CI $0.60-0.88, p=\mathrm{NA}$ ) [36]. The number of patients needed to treat (NNT) with dapagliflozin to prevent one primary event during the trial duration was 21 (95\% CI 15-38). Importantly, in a post hoc analysis including patients on concomitant sacubitril/valsartan therapy at baseline (nearly $10 \%$ of the trial population), the HR for the primary outcome was consistent amongst patients on- or off-sacubitril/valsartan. Despite the low percentage of patients treated with sacubitril/ valsartan at baseline, it appears that the benefits of SGLT2i therapy are additive to those afforded by neurohormonal modulating agents. Moreover, possible heterogeneity was observed according to New York Heart Association (NYHA) functional class, showing greater treatment benefit in class II patients, compared with class III or IV [35]. Regarding safety, the occurrence of adverse events (AEs) was low and similar between dapagliflozin and placebo, except for significantly more severe renal adverse events (AEs) in the placebo group (2.7\% vs. $1.6 \%, p=0.009)$ [36].

Table 2 and Table 3 summarize the ongoing HF-dedicated outcomes [36-38] and functional capacity clinical trials with SGLT2i, which will enhance the body of evidence for these agents in HF populations.

\section{From Clinical Trials to the Real World}

The SGLT2i positive impact on CV outcomes observed in CVOTs, specifically regarding HHF, was also observed in the real-world evidence (RWE) studies CVD-REAL and EMPRISE [41, 42].

CVD-REAL study included 309,056 T2D patients with or without CVD at baseline, newly treated with SGLT2i or other glucose-lowering drugs, from registries within six countries. All primary analyses showed a benefit of SGLT2i over other glucose-lowering drugs: HHF (HR 0.61, 95\% CI 0.51-0.73, $p<0.001$ ); all-cause mortality (HR $0.49,95 \%$ CI $0.41-0.57$, $p<0.001$ ), and HHF or death by any cause composite outcome (HR 0.54, 95\% CI 0.48-0.60, $p<0.001$ ) [42].

The ongoing EMPRISE study aims to assess empagliflozin's effectiveness, safety, and healthcare utilization in routine care in the USA, including data from 232,000
T2D patients newly initiated on empagliflozin or sitagliptin. After five months follow-up of the nearly 32,000 matched patients, empagliflozin decreased the risk of HHF by $50 \%$ (HR 0.50, 95\% CI 0.28-0.91, $p=\mathrm{NA}$ ), with consistent results in patients with or without baseline CVD [41].

The available data on SGLT2i, both from CVOTs and from RWE, has undoubtedly shifted the paradigm of T2D management in clinical practice from a focus on glycaemic control to a broader approach on $\mathrm{CV}$ event reduction, and also as a potential new class of drugs for HF treatment even in people without T2D. Given the impressive cardioprotective effects of SGLT2i, the results of the DAPA-HF trial were enthusiastically received. Results of other ongoing trials with SGLT2i in high-risk diabetic and non-diabetic cardiovascular populations are keenly awaited and should shed more light into possible differences in clinical outcomes and prognosis, most importantly in mortality and on potential beneficial effect on MI, which remains an active topic of investigation [27, 43].

\section{Potential Mechanisms Behind the Cardio-renal Benefits Observed with SGLT2i}

Although impressive results have been achieved with SGLT2i, there is a lack of knowledge of the mechanisms associated with the observed benefits.

SGLT2i inhibit glucose and sodium reabsorption in the kidneys, thus resulting in glycosuria. Their effects consequently include reductions in HbAlc, blood glucose levels and blood pressure (BP), but also reductions in body weight and adiposity, all mechanisms that may contribute to reducing cardiovascular risk and HF [27, 44]. The reduction in systolic and diastolic BP is reported to be about 3-7 and $2 \mathrm{mmHg}$, respectively, and seems to be independent of disease status or treatment with antihypertensive drugs [45]. Also, a reduction in body weight is consistently observed in individuals taking SGLT2i, but the magnitude of weight loss is modest (1 to $3 \mathrm{~kg}$ ) both in T2D and in obese patients without diabetes, due to counter-regulatory mechanisms striving to maintain body weight. It is unknown whether such effects can translate into reduced cardiovascular disease events, including HF [45].

However, the evidence indicates that the cardioprotective benefits behind SLGT2i go beyond roles in glycemia, BP control, and weight loss. Firstly, the glucose and BPlowering effects of SGLT2i compared with placebo are not sufficient to explain the outcomes observed in randomized clinical trials (RCT). Secondly, if the beneficial effects of SGLT2i were due exclusively to glycaemic or BP control, these effects should impact all CV outcomes. Although SGLT2i have a significant effect on the prevention of HF events, they are neutral in preventing atherothrombotic events such as stroke, with only a possible modest effect on MI. A 


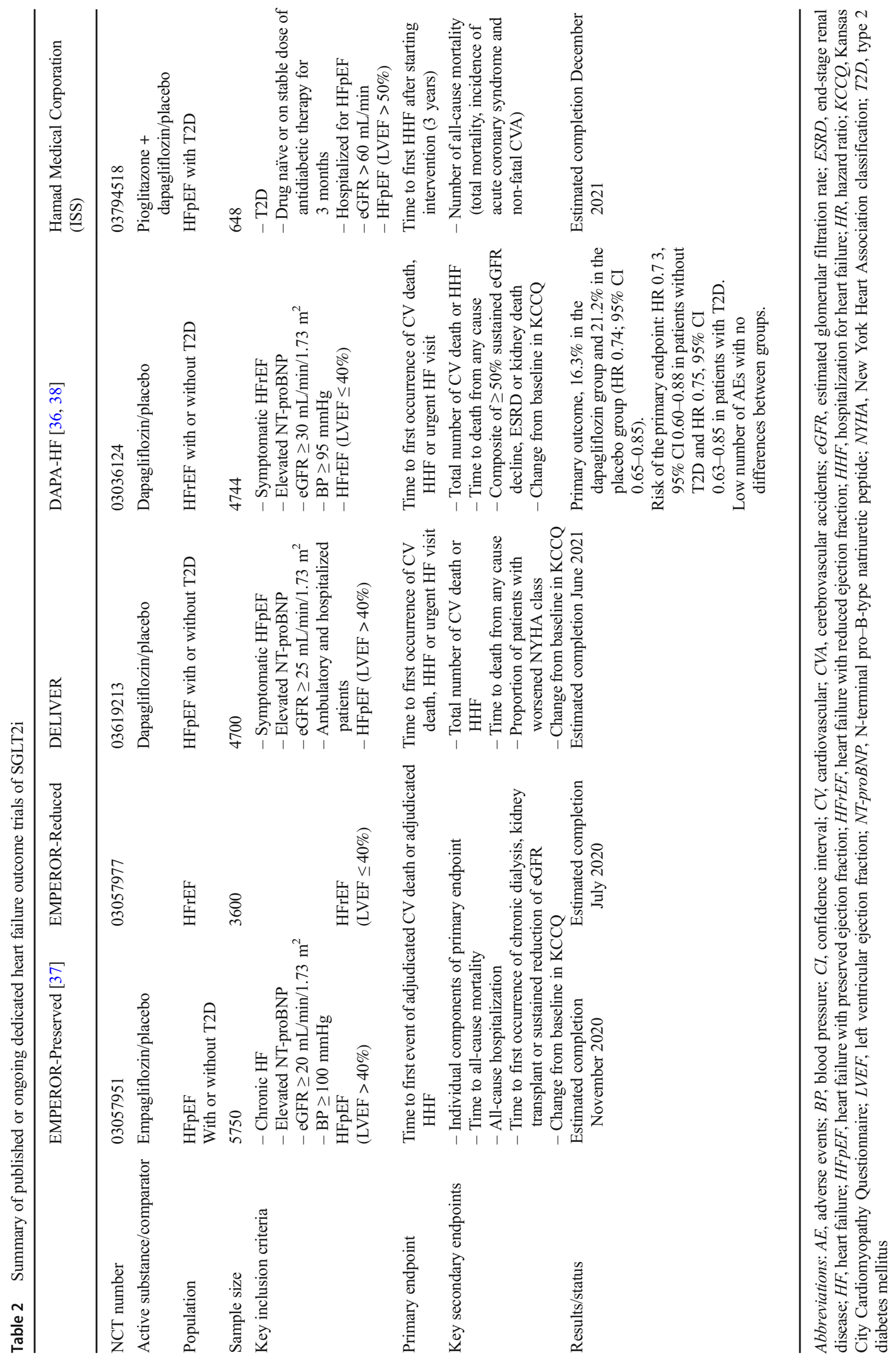


subanalysis from DECLARE-TIMI 58 suggested a reduction in type 2 MI, possibly by ischemic and not anti-thrombotic mechanisms [27, 43]. Additionally, the beneficial effects of SLGT2is are seen at similar proportions across patients with different levels of HbAlc and eGFR.

Several hypotheses have thus been postulated to explain the cardio-renal outcomes observed with SLGT2i, beyond effects on glycemia, BP and weight loss (Fig. 1).

\section{The "Super Fuel" Hypothesis}

The healthy myocardium is metabolically "omnivorous" and able to switch between different sources of energy; it can use carbohydrates, ketones, lactate and certain amino acids as fuel, but utilizes preferentially free fatty acids (FFA) for energy production, which yield substantial amounts of energy in the form of adenosine triphosphate (ATP) molecules, albeit at the expense of higher oxygen consumption [47]. Ketone bodies may also be used by the myocardium as the most energyefficient fuel source, producing the largest number of ATP molecules at the lowest oxygen expense.

In the diseased myocardium, there is an increased uptake of glucose and FFA into the cytosol, but this becomes uncoupled from their uptake and oxidation in the mitochondria, leading to an accumulation of metabolic intermediates, ultimately resulting in toxicity [48]. In patients treated with empagliflozin the induced glycosuria results in lower plasma glucose and insulin levels, with concomitant increased plasma glucagon (resembling a fasting state), leading to enhanced lipid mobilization [49, 50]. The lower ratio of insulin/ glucagon at the portal vein and the increased circulation of FFA stimulate ketogenesis in the liver [51].

This hypothesis, suggested by previous authors as the "thrifty substrate" hypothesis, postulates that SGLT2i cause a mild but persistent increase in the production of ketone bodies, in particular beta-hydroxybutyrate, which becomes, along with FFA, the main substrates for ATP production in the myocardium, in detriment of glucose. Because ketone bodies are more energy-efficient than FFA, this shift greatly improves the energetic efficiency of the heart [52] and reduces cytotoxicity [48].

Although animal studies have been conducted to test this hypothesis, it still lacks confirmatory clinical data to support it. A study in a non-diabetic porcine model subjected to MI showed that empagliflozin increases myocardial consumption of ketones at the same time that it reduces glucose consumption, with increased myocardial energetics leading to reverse remodelling at anatomical, metabolic and neurohormonal levels [46]. The same investigators are currently conducting a trial with empagliflozin (the EMPA-TROPISM study [53]), attempting to translate these results into the clinical arena.

\section{The Sodium-Hydrogen Exchanger Hypothesis}

One alluring hypothesis that has been put forward is that SLGT2i may offer cardio-renal benefits by directly binding to and inhibiting the sodium-hydrogen exchangers (NHE) in the heart and kidney [54]. The NHE1 isoform is ubiquitously distributed and is the predominant isoform expressed in the heart [55], whereas NHE3 expression is limited to epithelial cells of the gut and kidney, being responsible for most of the sodium reuptake after glomerular filtration [56, 57]. In HF, the activity of NHE1 in cardiomyocytes is markedly increased, leading to higher concentrations of $\mathrm{Na}^{+}$in the cytosol, which in turn triggers an increase in intracellular $\mathrm{Ca}^{2+}$ and ultimately lead to cardiomyocyte injury and cardiomyopathy [54].

Experimental models have shown that SLGT2i directly bind to NHE1 in cardiomyocytes, reducing cytoplasmic $\mathrm{Na}^{+}$ and $\mathrm{Ca}^{2+}$ levels [58-60]. It should be noted that the SLGT2 transporter is not expressed in the heart [61]; thus, SLGT2i cannot exert their action in cardiomyocytes via SLGT2 inhibition. It has been postulated that SLGT2i may also downregulate the activity of NH3 in the proximal tubule [62]. Animal models have shown that $\mathrm{NH} 3$ expression is increased in $\mathrm{HF}$ as a result of upregulation of mineralocorticoids, leading to fluid retention and peripheral oedema [63, 64]. Mineralocorticoid antagonists such as spironolactone inhibit both NHE1 and NHE3 and ameliorate experimental models of HF [65-71]. Interestingly, in the EMPA-REG OUTCOME trial, the CV benefits with empagliflozin were attenuated in patients receiving spironolactone at baseline [29]. However, the same effect was not observed in the DAPA-HF trial, where over $70 \%$ of the population received background therapy with aldosterone antagonists [35].

\section{The "Smart Diuretic" Hypothesis}

The "smart diuretic" hypothesis suggests that the favourable effects observed with SGLT2i are in part due to their more selective diuretic effects. SGLT2i have unique diuretic properties whereby they modulate the function of the proximal tubule, leading to natriuresis, glycosuria and ensuing osmotic diuresis [72]. The consequent sodium and volume reductions would result in lower preload and afterload, leading to improved cardiac loading conditions [73]. The proximal tubule action and natriuretic effect act as stimuli for tubuloglomerular feedback, resulting in afferent arteriolar vasoconstriction, thus lowering glomerular hypertension, and likely causing an antiproteinuric effect [73]. Besides volume contraction, SGLT2i have also been shown to increase haemoconcentration, possibly also associated to intrinsic renal mechanisms, such as the recovery of tubulointerstitial hypoxia and increased erythropoietin (EPO) production, mechanisms that require further clarification [74, 75]. It may be hypothesized that the haemoconcentration can lead to increased 


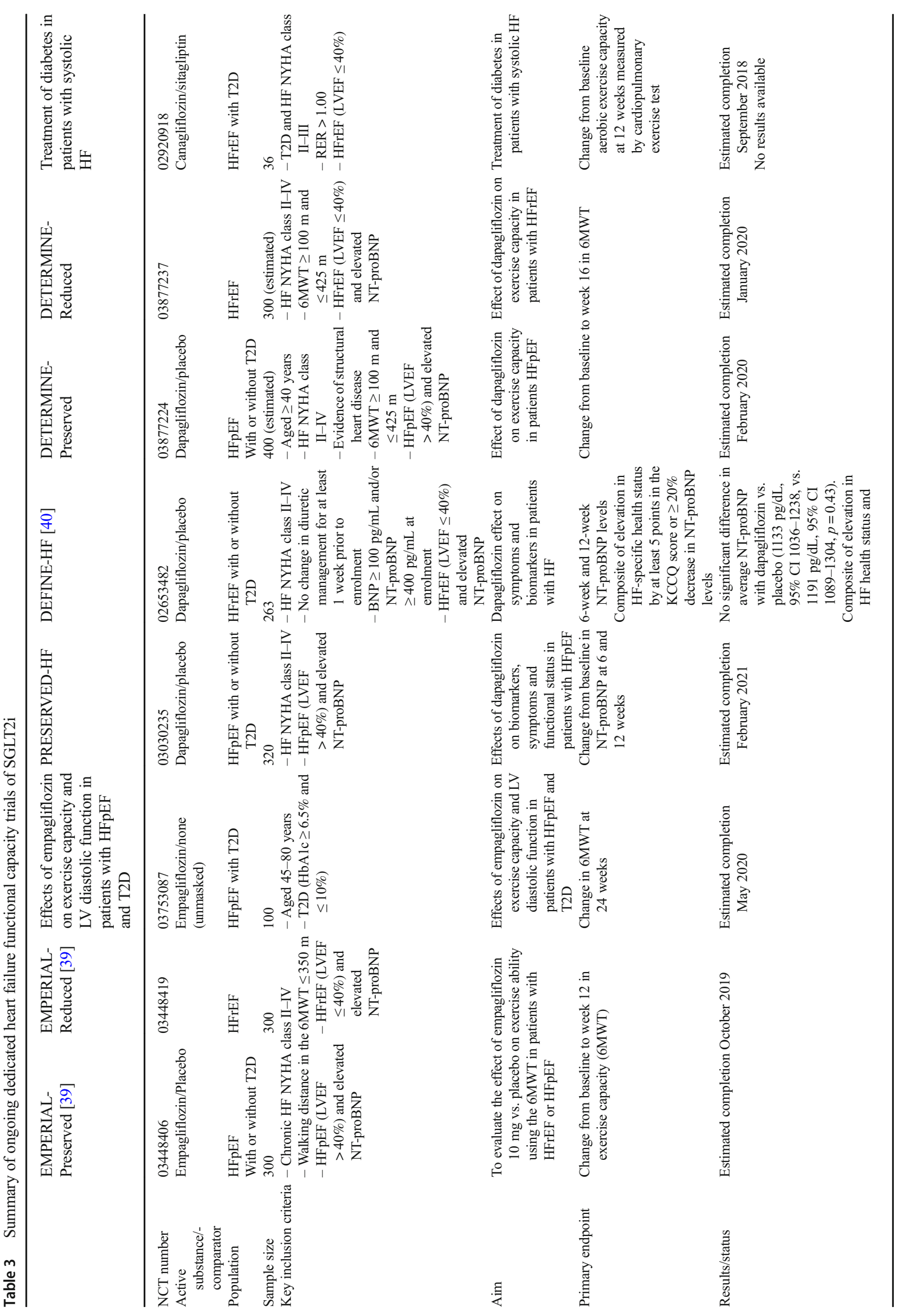


oxygen delivery to myocardial tissue and serve as a complementary mechanism to the "super fuel" hypothesis, further enhancing myocardial efficiency [52]. Furthermore, it has been proposed that SGLT2i have the ability to selectively reduce interstitial fluid, a property unique to this class, which may be particularly relevant for patients with congestive HF and interstitial oedema [72]. This differs from the drastic reduction in intravascular volume observed with loop diuretics, which may lead to compensatory mechanisms and neurohormonal activation, associated with deleterious effects [76]. Alternatively, a sympathoinhibitory afferent renal nerve signal is another possible mechanism to explain the absence of SGLT2i activation on the sympathetic nervous system, typically activated with diuretic therapies [77]. Other differences between SLGT2i and traditional diuretics include their uricosuric effect [78], as well as their ability to improve endothelial function and aortic stiffness [79-81].

\section{Other Proposed Mechanisms}

Multiple other mechanisms have been proposed to explain the early cardio-renal benefits of SGLT2i, including hypotheses that rely on leptin, calcium-calmodulin inhibition, visceral adipose tissue loss and direct vascular (arterial rigidity and central pressure) effects. The effect of SGLT2i on the secretion of leptin (which contributes to the retention of sodium and to the cardiac and renal fibrosis present in patients with obesity-related $\mathrm{HFpEF}$ ) may reduce $\mathrm{Na}^{+}$retention and the accumulation of visceral adipose tissue, namely epicardial fat, and thus ameliorate the effects of systemic inflammation on the vasculature and visceral organs [82, 83]. The recently published EMPA-HEART CardioLink-6 trial [84] added information to the SGLT2i CVOTs, with the inclusion of imaging parameters evaluations. EMPA-HEART aimed to determine whether the CV benefits of SGLT2i could be secondary to a reduction in LV mass, an important and independent predictor of MI, HF and mortality. Individuals with T2D, coronary artery disease and a normal LV mass index (LVMi), representative of the EMPA-REG OUTCOME cohort, were included. After six months, there was a significant reduction in LVMi (measured by cardiac magnetic resonance imaging) associated with empagliflozin [84]. Importantly, the observed reduction in LVMi appeared to occur without reductions in LV volumes, thus reflecting an overall reduction in LV wall thickness, with a greater magnitude of regression observed in patients with higher LVMi at baseline. However, the mechanisms behind the reduction in wall thickness remain to be elucidated, possibly relating to changes in interstitial water content or reduced cardiomyocyte mass. Other evidence from small studies (Moura, B et al. Empagliflozin: effects on the heart and 


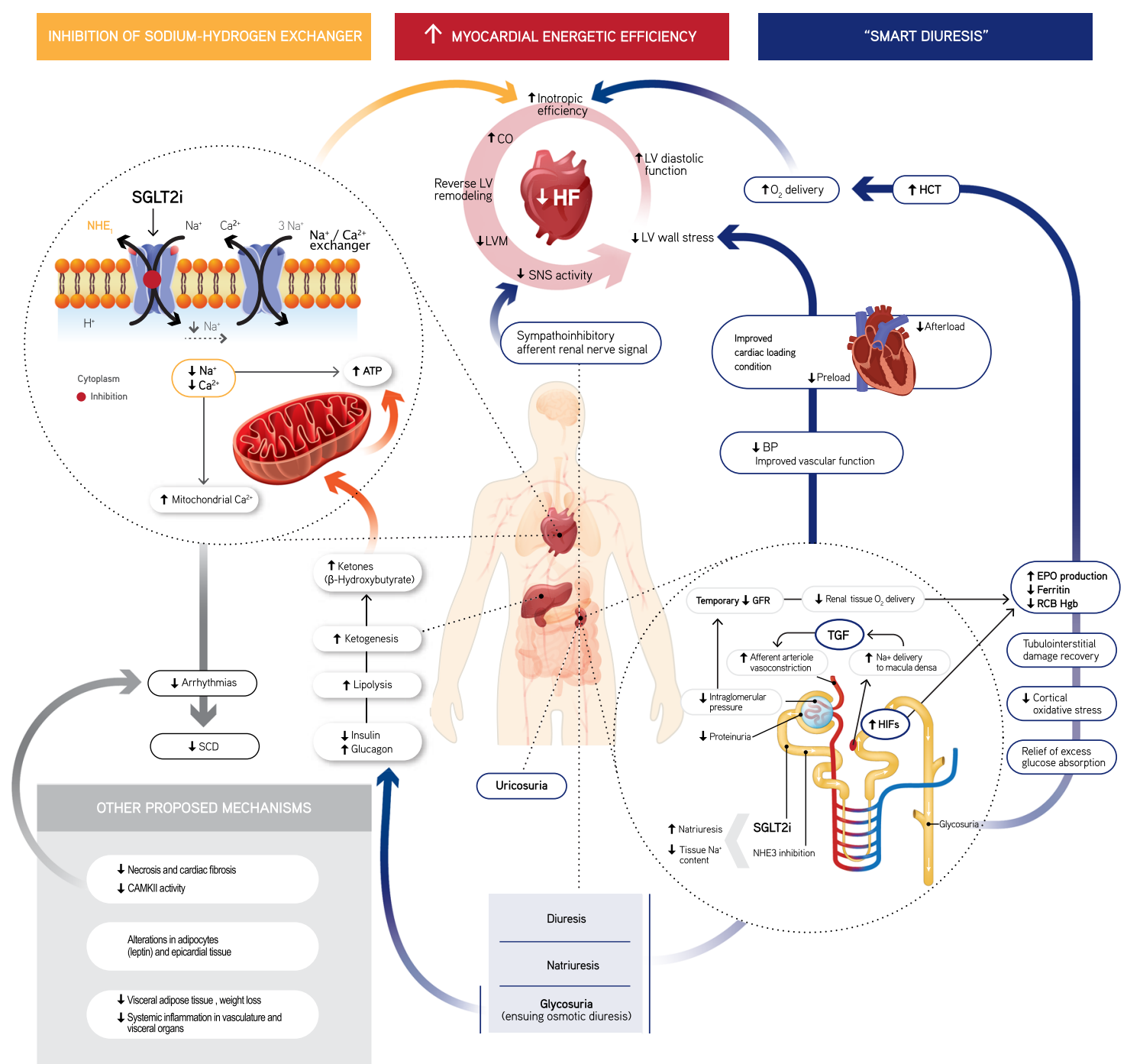

Fig. 1 Overview of postulated cardio-renal SGLT2i translational mechanisms and observed clinical outcomes. Abbreviations: ATP, adenosine triphosphate; CO, cardiac output; GFR, glomerular filtration rate; $\mathrm{BP}$, blood pressure; EPO, erythropoietin; Glu, glucose; HCT, haematocrit; $\mathrm{MCU}$, mitochondrial calcium uniporter; $\mathrm{Na}^{+}$, sodium; $\mathrm{Ca}^{2+}$, calcium; NHE; sodium hydrogen exchanger; NHE1 sodiumhydrogen exchanger 1; NHE3, sodium-hydrogen exchanger 3; SCD, sudden cardiac death; SGLT2i, sodium-glucose co-transporter 2 inhibitor; SNS, sympathetic nervous system; TGF, tubuloglomerular

vessels. P2059. ESC Congress 2019. 31 August-04 September 2019, Paris, France) showed that SGLT2i induces a decrease in atrial volume and an improvement in diastolic function beyond reverse remodelling [85].

Key translational mechanisms on CV physiology which are currently in need for further data with SGLT2i are listed in Table 4.

In conclusion, the various described hypotheses and mechanisms are not mutually exclusive and may all play a part in the observed cardio-renal outcomes with SGLT2i. Most likely, feedback; LV, left ventricle; LVM, left ventricle mass; $\mathrm{O}_{2}$, oxygen; RBC Hg, red blood cell haemoglobin; HIFs, hypoxia inducible factors; SCD, sudden cardiac death; CAMKII, calcium/calmodulin-dependent protein kinase II (adapted from refs. 46; 70; 71; 73; 75; 80; Verma A, et al. J Am Coll Cardiol.. 2018; doi: https://doi.org/10.1016/j.jacc.2017.12. 034.; Arjun S, et al. Cardiovasc Res. 2019; doi: https://doi.org/10.1093/ cvr/cvz105.; Mazer CD, et al. Circulation. 2019; doi: https://doi.org/10. 1161/CIRCULATIONAHA.119.044235.; Ottolia M, et al. J Mol Cell Cardiol. 2013; doi: https://doi.org/10.1016/j.yjmcc.2013.06.001.)

the hemodynamic, metabolic and tissue/cellular mechanisms work synergistically in promoting the observed benefits.

The ongoing mechanistic trials being conducted mostly in HF populations should be able to shed more light on the SGLT2i effects in myocardial bioenergetics, biomarkers and remodelling parameters (Table 5) [53, 86-89]. In addition, the ongoing trials evaluating functional capacity and quality of life (QoL), including both HFrEF and HFpEF patients (Table 3) $[39,40]$ should bring further insights to guide clinical practice. 


\section{Practical Considerations for SGLT2i Management in T2D Patients with HF}

\section{SGLT2i Safety Profile}

SGLT2i generally have a favourable efficacy and safety profile. The recommended doses for the different SGLT2i are reviewed in Supplementary table 1.

Genital mycotic infections are the most frequent AE reported, as well as an increase in urinary tract infections, although the later with no statistically significant differences compared with placebo. Other safety issues such as bone fractures and peripheral amputations have only been observed in one clinical trial with canagliflozin [21]. A number of rare AEs have been reported, including ketoacidosis and Fournier's gangrene, which have led to specific warnings by regulatory agencies. Nevertheless, there are specific measures that can be previously assured to prevent and to manage these events [90] (Supplementary table 2).

\section{Special Considerations for Management of HF Therapies and SGLT2i}

According to the 2016 ESC HF Guidelines, empagliflozin should be considered in T2D patients to delay or prevent the onset of HF and prolong life, as a class IIA, level B recommendation [1]. In the recent expert consensus update from the Heart Failure Association (HFA) of the ESC [91], it is recommended that dapagliflozin and canagliflozin should also be considered in T2D patients with established CVD or high CV risk to prevent or delay the onset of HF and HHF. These documents, however, do not specifically recommended dapagliflozin and canagliflozin to prolong life, in alignment with the recent ESC/EASD Guidelines for diabetes and pre-diabetes, where prognostic recommendations are reserved to empagliflozin based on CVOT data. Although in the HFA expert consensus, no specific recommendations for

Table 4 Key translational mechanisms in need for further data with SGLT2i

- Serum cardiac and renal biomarkers (e.g. NT-proBNP*, Gal-3, soluble ST2, other)

- Electrophysiological mechanisms

- Effects on sympathetic nervous system

- Effects on neurohormonal responses

- Effects of uric acid reduction

*iSGLT2 effects on NT-proBNP levels have been contradictory and require further confirmation in large RCTs of HF populations

Abbreviations: NT-proBNP, N-terminal pro-B-type natriuretic peptide; Gal-3, galectin-3; $S T 2$, suppression of tumorigenicity the use of SGLT2i could be made for patients with established HF, some practical considerations were highlighted. Upon initiation of an SGLT2i, an initial "dip" in eGFR can be noted in some patients (an average decrease of $3-5 \mathrm{~mL} / \mathrm{min}$ ), suggested as a positive marker for long-term preservation of renal function [91, 92]. This remains to be confirmed specifically in HF patients with or without $\mathrm{T} 2 \mathrm{D}$.

The observed effects of SGLT2i in eGFR may be similar to the effect noted upon initiation of angiotensinconverting enzyme inhibitors (ACEi) or angiotensin receptor blockers (ARB) therapy, and therefore caution may be recommended upon concomitant initiation of SGLT2i and renin-angiotensin-aldosterone system (RAAS) modulating therapies. The long-term renal preservation with both classes, however, may be synergistic considering their complementary mechanisms. Similarly, as most HF patients are managed with loop diuretics for congestion, adjustments to baseline diuretic therapy may be necessary upon SGLT2i initiation, based on adequate volume assessment and definition of volume status. Temporary discontinuation of SGLT2i and/or diuretic agents may be required to manage clinical hypovolemia and ketoacidosis (Supplementary table 2) [91]. Regarding the management of diuretics in HF, the HFA has recently published a position statement [93]. SGLT2i are described as "other potential agents" and recommended as third-line therapy in acute congestive HF for the management of diuretic resistance [93]. Importantly, no specific recommendations are considered for the concomitant use of SGLT2i and other diuretics in the ambulatory chronic HF setting, where SGLT2i therapy will most often be implemented [94]. It is worthwhile noting that the electrolyte disturbances and renal deterioration associated with traditional diuretic agents used in HF management are not observed with SGLT2i, which would facilitate clinical management.

Another challenge in the management of HF patients is the treatment-associated or underlying progression of diseaseassociated hypotension. As most disease-modifying HF therapies reduce BP, the addition of SGLT2i therapy (average BP reduction of 3-5 $\mathrm{mmHg}$ ) should be implemented with caution, particularly in patients with lower baseline BP. The strategy of pre-emptively reducing doses of non-disease-modifying therapies, such as loop diuretics, may allow for a safer introduction of SGLT2i without additive hypotension or dehydration, as is currently recommended for achieving target doses of disease-modifying agents. As previously highlighted, most patients in the DAPA-HF trial were well treated with background HF therapies (including over $93 \%$ on diuretics) and no mandatory adjustments to baseline therapy were required by protocol; unexpectedly, the addition of dapagliflozin demonstrated tolerability similar to placebo. 


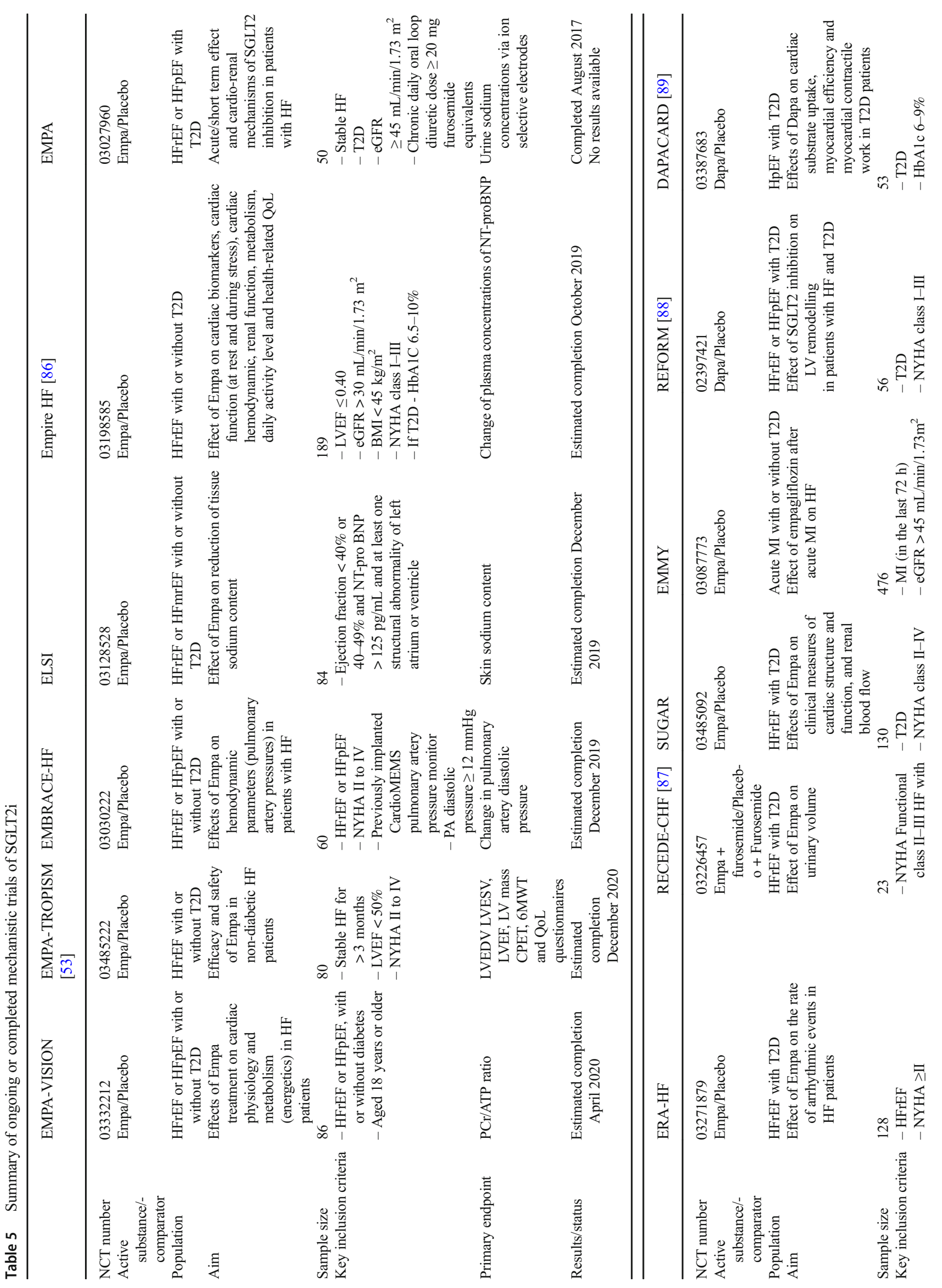




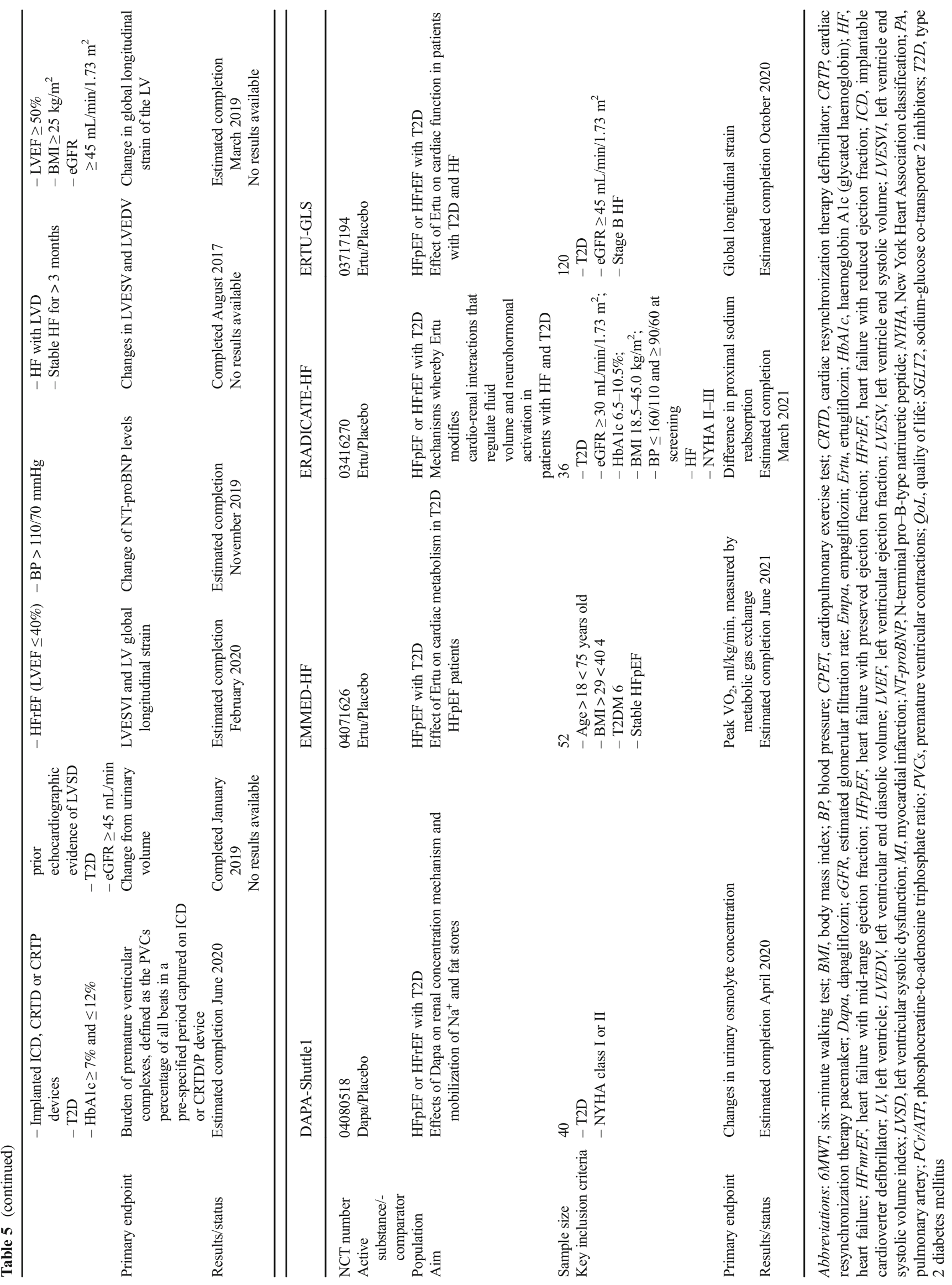


Table 6 Considerations for the management of glucose-lowering medications in patients with $\mathrm{HF}$ (adapted from refs. 1, 32, 90)

\begin{tabular}{|c|c|}
\hline Antidiabetic agent & Considerations for management of diabetes in HF patients \\
\hline Metformin & $\begin{array}{l}\text { Safe to use at all stages of HF in patients with preserved or moderately } \\
\text { reduced renal function (GFR }>30 \mathrm{~mL} / \mathrm{min}) \text {. } \\
\text { Lower risk of death and HHF compared with sulphonylureas and } \\
\text { insulin. } \\
\text { Should be discontinued in patients presenting acute conditions } \\
\text { associated with lactic acidosis (e.g. cardiogenic or distributive } \\
\text { shock). }\end{array}$ \\
\hline Sulphonylurea & $\begin{array}{l}\text { Limited data concerning the development of HF in individuals with } \\
\text { DM. } \\
\text { Effects on HF outcomes have been inconsistent. } \\
\text { Should be used with caution. }\end{array}$ \\
\hline Insulin & $\begin{array}{l}\text { Associated to weight gain and risk of hypoglycaemia. } \\
\text { May exacerbate fluid retention, leading to HF worsening. } \\
\text { Should be used with caution; close monitoring. }\end{array}$ \\
\hline Thiazolidinediones (glitazones) & $\begin{array}{l}\text { Cause sodium and water retention. } \\
\text { Increased risk of worsening HF and rates of HF hospitalization in } \\
\text { individuals with DM without HF. } \\
\text { Not recommended in patients with symptomatic HF, or at high risk for } \\
\text { developing HF. }\end{array}$ \\
\hline $\begin{array}{l}\text { Long-acting glucagon-like peptide } 1 \\
\text { receptor agonists (GLP-1) }\end{array}$ & $\begin{array}{l}\text { Low risk of hypoglycaemia. } \\
\text { Safe to use and improve glycaemic indices, but not beneficial in } \\
\text { preventing HF in patients at risk. } \\
\text { Neutral effect on HHF. } \\
\text { Use may be considered. }\end{array}$ \\
\hline $\begin{array}{l}\text { Dipeptidylpeptidase-4 inhibitors } \\
\text { (DPP4is; gliptins) }\end{array}$ & $\begin{array}{l}\text { Improved glycaemic indices but no evidence on cardiovascular } \\
\text { benefit. } \\
\text { Can increase the risk of HHF in patients with DM at high } \\
\text { cardiovascular risk (i.e. saxagliptin, possible with alogliptin). } \\
\text { Increases in LV volumes were observed with vildagliptin. Neutral } \\
\text { effects for sitagliptin and linagliptin. } \\
\text { Should not be considered in patients with HF, or at high risk for } \\
\text { developing HF. }\end{array}$ \\
\hline $\begin{array}{l}\text { Sodium-glucose co-transporter type } 2 \\
\text { inhibitors (SGLT2i) }\end{array}$ & $\begin{array}{l}\text { First class of glucose-lowering agents to demonstrate HF } \\
\text { hospitalization risk reduction in patients with DM. } \\
\text { Recommended for patients with T2D to reduce HF risk (class IA } \\
\text { recommendation). } \\
\text { Promising for treatment of established HF in patients with and } \\
\text { without DM. }\end{array}$ \\
\hline
\end{tabular}

Abbreviations: $D M$, diabetes mellitus; $G F R$, glomerular filtration rate; $H F$, heart failure; $H H F$, hospitalization for heart failure; $L V$, left ventricular; $T 2 D$, type 2 diabetes mellitus

\section{Considerations for Management of Antidiabetic Agents in Patients with HF}

According to the 2016 ESC HF Guidelines, glycaemic control should be implemented in a gradual and moderate manner, and metformin is recommended as the first-line oral hypoglycaemic drug for HF patients [1]. Considering this document, as well as more recent evidence and recommendations from the American Heart Association scientific statement on T2D and HF [95], in addition to the 2019 ESC/EASD diabetes guidelines [32], Table 6 summarizes the circumstances to consider when selecting and using antidiabetic agents in patients with HF.

\section{Unmet Medical Needs and Conclusions}

Despite the close pathophysiological relation between T2D and HF, cardiovascular outcome trials with SGLT2i were not designed to test their efficacy and safety, specifically in HF patients. Only a small proportion of patients in the EMPAREG OUTCOME trial, CANVAS program and DECLARE- 
TIMI 58 trial had a diagnosis of HF at baseline (and in those who had, the HF phenotype was not initially characterized). DAPA-HF was the first in class RCT to demonstrate a significant impact of an SGLT2i vs. placebo, on top of optimal medical therapy, in terms of morbidity and mortality in patients with HFrEF, irrespective of the presence of T2D [35, 38].

Similarly, the smaller DEFINE-HF trial supported these results by showing beneficial effects of dapagliflozin on HFrelated QoL, and symptoms in HFrEF patients [40], and dapagliflozin has now been given a "fast track" status by the FDA for a proposed indication to reduce CV death or worsening HF.

The results from ongoing SGLT2i HF-dedicated outcomes trials are expected to lead to a growing potential for SGLT2i use in HF clinical practice (in the same way that the EMPA-REG OUTCOME trial drove a major shift in T2D management) and will answer the remaining questions of whether the results observed in DAPA-HF extend to other SGLT2i, and if the beneficial effects also include the HFpEF population.

Additional potential usage of SGLT2i may be anticipated for the treatment of acute HF (AHF), which is the major cause of HHF, and for which there are no currently available therapies that improve clinical outcomes [96]. The EMPA Acute Heart Failure, EMPAG-HF and EMPULSE trials are underway to study the effects of SGLT2i on clinical outcomes in the AHF population (ClinicalTrials.gov Identifiers: NCT03554200, NCT04049045 and NCT04157751, respectively), while the EMPA-RESPONSE study has been published recently [97].

Another limitation of the RCT evidence with SGLT2 $i$ is that the reported trials were designed to test $\mathrm{CV}$ outcomes, but not SGLT2i CV actions, for which mechanistic clinical trials are currently underway (Table 5). The results of ongoing trials are eagerly awaited by the scientific HF community, especially considering the growing number of HF patients worldwide.

In summary, the evidence to date tells us that SGLT2i offer cardioprotection for HF patients (particularly those with HFrEF) and also to those at risk for developing HF, benefits that appear to be independent of glycaemic control, and that are observed in populations with and without T2D. The mechanisms underlying this protection can act in various ways and be complementary or synergistic.

Deepening this knowledge may help to identify more targeted therapies in the future, according to the patients' overall $\mathrm{CV}$ and HF profile.

Undoubtedly, a new chapter of this history has begun.

Acknowledgements The authors acknowledge writing assistance provided by Ana Santos from Prime Focus, funded by Boehringer Ingelheim.
Authors' Contributions All the authors researched data for the article, discussed the content, wrote the manuscript and reviewed and edited it before submission.

Funding Information This paper had a non-restrictive financial support of Boehringer Ingelheim and Lilly Portugal.

\section{Compliance with Ethical Standards}

Competing Interests DB reports personal fees from Boehringer Ingelheim as an advisory board member, during the conduct of the study, and personal consultancy fees from AstraZeneca, Novartis, Orion, Pfizer, Roche Diagnostics, Servier and Vifor pharma, outside the submitted work; PB reports personal fees and non-financial support from Boehringer Ingelheim as an advisory board member, during the conduct of the study, and personal fees and non-financial support from AstraZeneca, Roche Diagnostics, OM Pharma, Servier and Novartis, outside the submitted work; DC reports personal fees from AstraZeneca, Boehringer Ingelheim, Eli Lilly and Mundipharma as an advisor and speakers bureau, outside the submitted work; JF reports personal fees from Boehringer Ingelheim, as an advisory board member, during the conduct of the study, and outside the submitted work; RFC reports nonfinancial support from Boehringer Ingelheim, during the conduct of the study, and personal fees from Boehringer Ingelheim, AstraZeneca and MSD, outside the submitted work; BM reports non-financial support from Boehringer Ingelheim, for flights to meeting, during the conduct of the study, and personal fees from Boehringer Ingelheim and AstraZeneca, outside the submitted work; RTM reports personal fees from Boehringer Ingelheim, as a Medical Department employee at Boehringer Ingelheim, during the conduct of the study, and outside the submitted work; CF reports personal fees from Boehringer Ingelheim as an advisory board member and grants from Boehringer Ingelheim for manuscript preparation, during the conduct of the study; FF and JSC have nothing to disclose.

\section{Ethics Approval Not applicable.}

Open Access This article is licensed under a Creative Commons Attribution 4.0 International License, which permits use, sharing, adaptation, distribution and reproduction in any medium or format, as long as you give appropriate credit to the original author(s) and the source, provide a link to the Creative Commons licence, and indicate if changes were made. The images or other third party material in this article are included in the article's Creative Commons licence, unless indicated otherwise in a credit line to the material. If material is not included in the article's Creative Commons licence and your intended use is not permitted by statutory regulation or exceeds the permitted use, you will need to obtain permission directly from the copyright holder. To view a copy of this licence, visit http://creativecommons.org/licenses/by/4.0/.

\section{References}

1. Ponikowski P, Voors AA, Anker SD, et al. 2016 ESC Guidelines for the diagnosis and treatment of acute and chronic heart failure. Eur Heart J. 2016;37:2129-200. https://doi.org/10.1093/eurheartj/ ehw128.

2. Ponikowski P, Anker SD, AlHabib KF, et al. Heart failure: Preventing disease and death worldwide. ESC Heart Fail. 2014;1: $4-25$. 
3. Savarese G, Lund LH. Global public health burden of heart failure. Card Fail Rev. 2017;3:7-11. https://doi.org/10.15420/cfr.2016:25: 2.

4. Benjamin EJ, Blaha MJ, Chiuve SE, et al. Heart disease and stroke statistics'2017 update: A report from the American Heart Association. Circulation. 2017;135:e146-603.

5. Fonseca C, Brás D, Araújo I, Ceia F. Heart failure in numbers: Estimates for the 21st century in Portugal. Rev Port Cardiol. 2018;37:97-104. https://doi.org/10.1016/j.repc.2017.11.010.

6. Roger VL, Weston SA, Redfield MM, et al. Trends in heart failure incidence and survival in a community-based population. JAMA. 2004;292:344-50. https://doi.org/10.1001/jama.292.3.344.

7. Stewart S, Ekman I, Ekman T, et al. Population impact of heart failure and the most common forms of cancer: A study of 1162 309 hospital cases in Sweden (1988 to 2004). Circ Cardiovasc Qual Outcomes. 2010;3:573-80. https://doi.org/10.1161/ CIRCOUTCOMES.110.957571.

8. Lesyuk W, Kriza C, Kolominsky-Rabas P. Cost-of-illness studies in heart failure: A systematic review 2004-2016. BMC Cardiovasc Disord. 2018;18:74. https://doi.org/10.1186/s12872-018-0815-3.

9. Zhou B, Lu Y, Hajifathalian K, et al. Worldwide trends in diabetes since 1980: A pooled analysis of 751 population-based studies with 4.4 million participants. Lancet. 2016;387:1513-30. https://doi.org/ 10.1016/S0140-6736(16)00618-8.

10. IDF - International Diabetes Federation (2019) IDF diabetes atlas, 9th ed.

11. Guariguata L, Whiting DR, Hambleton I, et al. Global estimates of diabetes prevalence for 2013 and projections for 2035. Diabetes Res Clin Pract. 2014;103:137-49. https://doi.org/10.1016/j.diabres. 2013.11.002.

12. Sarwar N, Gao P, Kondapally Seshasai SR, et al. Diabetes mellitus, fasting blood glucose concentration, and risk of vascular disease: A collaborative meta-analysis of 102 prospective studies. Lancet. 2010;375:2215-22. https://doi.org/10.1016/S0140-6736(10) 60484-9.

13. Kannel WB, Hjortland M, Castelli WP. Role of diabetes in congestive heart failure: the Framingham study. Am J Cardiol. 1974;34: 29-34. https://doi.org/10.1016/0002-9149(74)90089-7.

14. Thrainsdottir IS, Aspelund T, Thorgeirsson G, et al. The association between glucose abnormalities and heart failure in the populationbased Reykjavík Study. Diabetes Care. 2005;28:612-6. https://doi. org/10.2337/diacare.28.3.612.

15. Ofstad AP, Atar D, Gullestad L, et al. The heart failure burden of type 2 diabetes mellitus - A review of pathophysiology and interventions. Heart Fail Rev. 2018;23:303-23. https://doi.org/10.1007/ s10741-018-9685-0.

16. Bogner HR, Miller SD, de Vries HF, et al. Assessment of cost and health resource utilization for elderly patients with heart failure and diabetes mellitus. J Card Fail. 2010;16:454-60. https://doi.org/10. 1016/j.cardfail.2010.01.007.

17. Cavender MA, Steg PG, Smith SC, et al. Impact of diabetes mellitus on hospitalization for heart failure, cardiovascular events, and death: outcomes at 4 years from the reduction of atherothrombosis for continued health $(\mathrm{REACH})$ registry. Circulation. 2015;132:923-31. https://doi.org/10.1161/CIRCULATIONAHA. 114.014796.

18. Samia El Hayek MM, Beydoun MF, Azar S. Antidiabetic medications in patients with heart failure. Minerva Endocrinol. 2017;42: 53-63. https://doi.org/10.23736/S0391-1977.16.02349-X.

19. Tamargo J. Sodium-glucose cotransporter 2 inhibitors in heart failure: Potential mechanisms of action, adverse effects and future developments. Eur Cardiol Rev. 2019;14:23-32. https://doi.org/10. 15420/ecr.2018.34.2.

20. Zinman B, Wanner C, Lachin JM, et al. Empagliflozin, cardiovascular outcomes, and mortality in type 2 diabetes. N Engl J Med. 2015;373:2117-28. https://doi.org/10.1056/NEJMoa1504720.
21. Neal B, Perkovic V, Mahaffey KW, et al. Canagliflozin and cardiovascular and renal events in type 2 diabetes. $\mathrm{N}$ Engl $\mathrm{J}$ Med. 2017;377:644-57. https://doi.org/10.1056/NEJMoa1611925.

22. Wiviott SD, Raz I, Bonaca MP, et al. Dapagliflozin and cardiovascular outcomes in type 2 diabetes. N Engl J Med. 2018;380:347-57. https://doi.org/10.1056/nejmoa1812389.

23. Fitchett D, Butler J, Van De Borne P, et al. Effects of empagliflozin on risk for cardiovascular death and heart failure hospitalization across the spectrum of heart failure risk in the EMPA-REG OUTCOME VR trial. Eur Heart J. 2018;39:363-70. https://doi. org/10.1093/eurheartj/ehx511.

24. Packer M. Reconceptualization of the molecular mechanism by which sodium-glucose cotransporter 2 inhibitors reduce the risk of heart failure events. Circulation. 2019;140:443-5. https://doi. org/10.1161/circulationaha.119.040909.

25. Kato ET, Silverman MG, Mosenzon O, et al. Effect of dapagliflozin on heart failure and mortality in type 2 diabetes mellitus. Circulation. 2019;139:2528-36. https://doi.org/10.1161/ CIRCULATIONAHA.119.040130.

26. Zelniker TA, Wiviott SD, Raz I, et al. SGLT2 inhibitors for primary and secondary prevention of cardiovascular and renal outcomes in type 2 diabetes: a systematic review and meta-analysis of cardiovascular outcome trials. Lancet. 2019;393:31-9. https://doi.org/10. 1016/S0140-6736(18)32590-X.

27. Monami M, Dicembrini I, Mannucci E. Effects of SGLT-2 inhibitors on mortality and cardiovascular events: a comprehensive metaanalysis of randomized controlled trials. Acta Diabetol. 2017;54: 19-36. https://doi.org/10.1007/s00592-016-0892-7.

28. Fitchett D, Zinman B, Wanner C, et al. Heart failure outcomes with empagliflozin in patients with type 2 diabetes at high cardiovascular risk: Results of the EMPA-REG OUTCOME® trial. Eur Heart J. 2016;37:1526-34. https://doi.org/10.1093/eurheartj/ehv728.

29. Wanner C, Lachin JM, Inzucchi SE, et al. Empagliflozin and clinical outcomes in patients with type 2 diabetes mellitus, established cardiovascular disease, and chronic kidney disease. Circulation. 2018;137:119-29. https://doi.org/10.1161/CIRCULATIONAHA. 117.028268

30. Perkovic V, Jardine MJ, Neal B, et al. Canagliflozin and renal outcomes in type 2 diabetes and nephropathy. N Engl J Med. 2019;380:2295-306. https://doi.org/10.1056/NEJMoa1811744.

31. Cosentino F, Grant PJ, Aboyans V, et al. 2019 ESC Guidelines on diabetes, pre-diabetes, and cardiovascular diseases developed in collaboration with the EASD. Eur Heart J. 2019;41:255-323. https://doi.org/10.1093/eurheartj/ehz486.

32. Matthews DR, Paldánius PM, Proot P, et al. Glycaemic durability of an early combination therapy with vildagliptin and metformin versus sequential metformin monotherapy in newly diagnosed type 2 diabetes (VERIFY): a 5-year, multicentre, randomised, doubleblind trial. Lancet. 2019;394:1519-29. https://doi.org/10.1016/ S0140-6736(19)32131-2.

33. Cannon CP, McGuire DK, Pratley R, et al. Design and baseline characteristics of the eValuation of ERTugliflozin efflcacy and Safety Cardio Vascular outcomes trial (VERTIS-CV). Am Heart J. 2018;206:11-23. https://doi.org/10.1016/j.ahj.2018.08.016.

34. Figtree GA, Rådholm K, Barrett TD, et al. Effects of canagliflozin on heart failure outcomes associated with preserved and reduced ejection fraction in type 2 diabetes mellitus. Circulation. 2019;139: 2591-3. https://doi.org/10.1161/CIRCULATIONAHA.119. 040057.

35. McMurray JJV, Solomon SD, Inzucchi SE, et al. Dapagliflozin in patients with heart failure and reduced ejection fraction. $\mathrm{N}$ Engl $\mathrm{J}$ Med. 2019;381:1995-2008. https://doi.org/10.1056/ NEJMoa1911303.

36. Anker SD, Butler J, Filippatos GS, et al. Evaluation of the effects of sodium-glucose co-transporter 2 inhibition with empagliflozin on morbidity and mortality in patients with chronic heart failure and a 
preserved ejection fraction: rationale for and design of the EMPEROR-Preserved Trial. Eur J Heart Fail. 2019;21:1279-87. https://doi.org/10.1002/ejhf.1596.

37. McMurray JJV, DeMets DL, Inzucchi SE, et al. A trial to evaluate the effect of the sodium-glucose co-transporter 2 inhibitor dapagliflozin on morbidity and mortality in patients with heart failure and reduced left ventricular ejection fraction (DAPA-HF). Eur J Heart Fail. 2019;21:665-75. https://doi.org/10.1002/ejhf.1432.

38. McMurray JJV, DeMets DL, Inzucchi SE, et al. The Dapagliflozin and Prevention of Adverse-Outcomes in Heart Failure (DAPA-HF) trial: baseline characteristics. Eur J Heart Fail. 2019;21:1402-11. https://doi.org/10.1002/ejhf.1548.

39. Patorno E, Pawar A, Franklin JM, et al. Empagliflozin and the risk of heart failure hospitalization in routine clinical care. Circulation. 2019;139:2822-30. https://doi.org/10.1161/circulationaha.118. 039177.

40. Kosiborod M, Cavender MA, Fu AZ, et al. Lower risk of heart failure and death in patients initiated on sodium-glucose cotransporter-2 inhibitors versus other glucose-lowering drugs. Circulation. 2017;136:249-59. https://doi.org/10.1161/ circulationaha.117.029190.

41. Furtado RHM, Bonaca MP, Raz I, et al. Dapagliflozin and cardiovascular outcomes in patients with type 2 diabetes mellitus and previous myocardial infarction. Circulation. 2019;139:2516-27. https://doi.org/10.1161/CIRCULATIONAHA.119.039996.

42. Mudaliar S, Alloju S, Henry RR. Can a shift in fuel energetics explain the beneficial cardiorenal outcomes in the EMPA-REG OUTCOME Study? A unifying hypothesis. Diabetes Care. 2016;39:1115-22. https://doi.org/10.2337/dc16-0542.

43. Pereira MJ, Eriksson JW. Emerging role of SGLT-2 inhibitors for the treatment of obesity. Drugs. 2019;79:219-30. https://doi.org/10. 1007/s40265-019-1057-0.

44. Wende AR, Brahma MK, McGinnis GR, Young ME. Metabolic origins of heart failure. JACC Basic to Transl Sci. 201(2):297310. https://doi.org/10.1016/J.JACBTS.2016.11.009.

45. Maack C, Lehrke M, Backs J, et al. Heart failure and diabetes: Metabolic alterations and therapeutic interventions: A state-of-theart review from the translational research committee of the heart failure association-european society of cardiology. Eur Heart J. 2018;39:4243-54. https://doi.org/10.1093/eurheartj/ehy596.

46. Ferrannini E, Baldi S, Frascerra S, et al. Shift to fatty substrate utilization in response to sodium-glucose cotransporter 2 inhibition in subjects without diabetes and patients with type 2 diabetes. Diabetes. 2016;65:1190-5. https://doi.org/10.2337/db15-1356.

47. Ferrannini E, Muscelli E, Frascerra S, et al. Metabolic response to sodium-glucose cotransporter 2 inhibition in type 2 diabetic patients. J Clin Invest. 2014;124:499-508. https://doi.org/10.1172/ JCI72227.

48. McGarry JD, Foster DW. Regulation of hepatic fatty acid oxidation and ketone body production. Annu Rev Biochem. 1980;49:395420. https://doi.org/10.1146/annurev.bi.49.070180.002143.

49. Ferrannini E, Mark M, Mayoux E. CV protection in the EMPAREG OUTCOME trial: A thrifty substrate hypothesis. Diabetes Care. 2016;39:1108-14. https://doi.org/10.2337/dc16-0330.

50. Santos-Gallego CG, Requena-Ibanez JA, San Antonio R, et al. Empagliflozin ameliorates adverse left ventricular remodeling in nondiabetic heart failure by enhancing myocardial energetics. J Am Coll Cardiol. 2019;73:1931-44. https://doi.org/10.1016/j.jacc. 2019.01.056.

51. Santos-Gallego CG, Garcia-Ropero A, Mancini D, et al. Rationale and design of the EMPA-TROPISM Trial (ATRU-4): Are the "Cardiac Benefits" of empagliflozin independent of its hypoglycemic activity? Cardiovasc Drugs Ther. 2019;33:87-95. https://doi. org/10.1007/s10557-018-06850-0.

52. Packer M. Activation and inhibition of sodium-hydrogen exchanger is a mechanism that links the pathophysiology and treatment of diabetes mellitus with that of heart failure. Circulation. 2017;136: 1548-59. https://doi.org/10.1161/CIRCULATIONAHA.117. 030418.

53. Padan E, Landau M. Sodium-proton $(\mathrm{Na}+\mathrm{H}+)$ antiporters: Properties and roles in health and disease. Met Ions Life Sci. 2016;2016(16):391-458. https://doi.org/10.1007/978-3-31921756-7 12.

54. Donowitz $\mathrm{M}$, Mohan $\mathrm{S}$, Zhu CX, et al. NHE3 regulatory complexes. J Exp Biol. 2009;212:1638-46. https://doi.org/10.1242/ jeb.028605

55. Girardi ACC, Di Sole F. Deciphering the mechanisms of the $\mathrm{Na}+$ $/ \mathrm{H}+$ exchanger-3 regulation in organ dysfunction. Am J Physiol Physiol. 2012;302:C1569-87. https://doi.org/10.1152/ajpcell. 00017.2012

56. Uthman L, Koeman A, Jancev M, et al. Class effects of SGLT2 inhibitors in mouse cardiomyocytes and hearts: inhibition of $\mathrm{Na}+/$ $\mathrm{H}+$ exchanger, lowering of cytosolic $\mathrm{Na}+$ and vasodilation. Diabetologia. 2018;61:722-6. https://doi.org/10.1007/s00125017-4509-7.

57. Baartscheer A, Schumacher CA, Wüst RCI, et al. Empagliflozin decreases myocardial cytoplasmic $\mathrm{Na}+$ through inhibition of the cardiac $\mathrm{Na}+\mathrm{H}+$ exchanger in rats and rabbits. Diabetologia. 2017;60:568-73. https://doi.org/10.1007/s00125-016-4134-x.

58. Mustroph J, Wagemann O, Lücht CM, et al. Empagliflozin reduces $\mathrm{ca} /$ calmodulin-dependent kinase ii activity in isolated ventricular cardiomyocytes. ESC Hear Fail. 2018;5:642-8. https://doi.org/10. 1002/ehf2.12336.

59. Heerspink HJL, Perkins BA, Fitchett DH, et al. Sodium glucose cotransporter 2 inhibitors in the treatment of diabetes mellitus. Circulation. 2016;134:752-72. https://doi.org/10.1161/ CIRCULATIONAHA.116.021887.

60. Gallo LA, Wright EM, Vallon V. Probing SGLT2 as a therapeutic target for diabetes: basic physiology and consequences. Diabetes Vasc Dis Res. 2015;12:78-89. https://doi.org/10.1177/ 1479164114561992.

61. Lütken SC, Kim SW, Jonassen T, et al. Changes of renal AQP2, $\mathrm{ENaC}$, and NHE3 in experimentally induced heart failure: response to angiotensin II AT1 receptor blockade. Am J Physiol Renal Physiol. 2009;297:F1678-88. https://doi.org/10.1152/ajprenal. 00010.2009

62. Inoue BH, dos Santos L, Pessoa TD, et al. Increased NHE3 abundance and transport activity in renal proximal tubule of rats with heart failure. Am J Physiol Integr Comp Physiol. 2012;302:R16674. https://doi.org/10.1152/ajpregu.00127.2011.

63. Karmazyn M, Sostaric JV, Gan XT. The myocardial Na+/H+ exchanger: a potential therapeutic target for the prevention of myocardial ischaemic and reperfusion injury and attenuation of postinfarction heart failure. Drugs. 2001;61:375-89. https://doi. org/10.2165/00003495-200161030-00006.

64. Drumm K, Kress TR, Gassner B, et al. Aldosterone stimulates activity and surface expression of NHE3 in human primary proximal tubule epithelial cells (RPTEC). Cell Physiol Biochem. 2006;17:21-8. https://doi.org/10.1159/000091456.

65. Yamamuro M, Yoshimura M, Nakayama M, et al. Direct effects of aldosterone on cardiomyocytes in the presence of normal and elevated extracellular sodium. Endocrinology. 2006;147:1314-21. https://doi.org/10.1210/en.2005-1244.

66. Zhang M, Chen J, Liu S, et al. The role of Na+-H+ exchanger isoform 1 in aldosterone-induced glomerulosclerosis in vivo. Ren Fail. 2009;31:726-35. https://doi.org/10.3109/ 08860220903134571

67. Young M, Funder J. Mineralocorticoid action and sodium-hydrogen exchange: studies in experimental cardiac fibrosis. Endocrinology. 2003;144:3848-51. https://doi.org/10.1210/en. 2003-0039. 
68. Carreño JE, Verdugo FJ, Contreras F, et al. Spironolactone inhibits the activity of the $\mathrm{Na}+\mathrm{H}+$ exchanger in the aorta of mineralocorticoid-induced hypertensive rats. J Renin Angiotensin Aldosterone Syst. 2015;16:1225-31. https://doi.org/10.1177/ 1470320315587193 .

69. Fujisawa $\mathrm{G}$, Okada $\mathrm{K}$, Muto $\mathrm{S}$, et al. $\mathrm{Na} / \mathrm{H}$ exchange isoform 1 is involved in mineralocorticoid/salt-induced cardiac injury. Hypertension. 2003;41:493-8. https://doi.org/10.1161/01.HYP. 0000056769.73726.E5.

70. Verma S, McMurray JJV. SGLT2 inhibitors and mechanisms of cardiovascular benefit: a state-of-the-art review. Diabetologia. 2018;61:2108-17. https://doi.org/10.1007/s00125-018-4670-7.

71. Verma S, McMurray JJV, Cherney DZI. The metabolodiuretic promise of sodium-dependent glucose cotransporter 2 inhibition: The search for the sweet spot in heart failure. JAMA Cardiol. 2017;2:939-40. https://doi.org/10.1001/jamacardio.2017.1891.

72. Inzucchi SE, Zinman B, Fitchett D, et al. How Does Empagliflozin Reduce Cardiovascular Mortality? Insights From a Mediation Analysis of the EMPA-REG OUTCOME Trial. Diabetes Care. 2018;41:356-63. https://doi.org/10.2337/dc17-1096.

74. Sano M, Takei M, Shiraishi Y, Suzuki Y. Increased Hematocrit During Sodium-Glucose Cotransporter 2 Inhibitor Therapy Indicates Recovery of Tubulointerstitial Function in Diabetic Kidneys. J Clin Med Res. 2016;8:844-847; 10.14740/jocmr2760w.

74. Hallow KM, Helmlinger G, Greasley PJ, et al. Why do SGLT2 inhibitors reduce heart failure hospitalization? A differential volume regulation hypothesis. Diabetes Obes Metab. 2018;20:47987. https://doi.org/10.1111/dom.13126.

75. Jordan J, Tank J, Heusser K, et al. The effect of empagliflozin on muscle sympathetic nerve activity in patients with type II diabetes mellitus. J Am Soc Hypertens. 2017;11:604-12. https://doi.org/10. 1016/j.jash.2017.07.005.

76. Wilcox CS, Shen W, Boulton DW, et al. Interaction Between the Sodium-Glucose-Linked Transporter 2 Inhibitor Dapagliflozin and the Loop Diuretic Bumetanide in Normal Human Subjects. J Am Heart Assoc. 2018;7.pii:e007046; 10.1161/JAHA.117.007046.

77. Solini A, Giannini L, Seghieri M, et al. Dapagliflozin acutely improves endothelial dysfunction, reduces aortic stiffness and renal resistive index in type 2 diabetic patients: a pilot study. Cardiovasc Diabetol. 2017;16:138. https://doi.org/10.1186/ s12933-017-0621-8.

78. Li H, Shin SE, Seo MS, et al. The anti-diabetic drug dapagliflozin induces vasodilation via activation of PKG and Kv channels. Life Sci. 2018;197:46-55. https://doi.org/10.1016/j.lfs.2018.01.032.

79. Chilton R, Tikkanen I, Cannon CP, et al. Effects of empagliflozin on blood pressure and markers of arterial stiffness and vascular resistance in patients with type 2 diabetes. Diabetes Obes Metab. 2015;17:1180-93. https://doi.org/10.1111/dom.12572.

80. Packer M, Kitzman DW. Obesity-Related Heart Failure With a Preserved Ejection Fraction: The Mechanistic Rationale for Combining Inhibitors of Aldosterone, Neprilysin, and SodiumGlucose Cotransporter-2. JACC Hear Fail. 2018;6:633-9. https:// doi.org/10.1016/j.jchf.2018.01.009.

81. Packer M. Do sodium-glucose co-transporter-2 inhibitors prevent heart failure with a preserved ejection fraction by counterbalancing the effects of leptin? A novel hypothesis. Diabetes, Obes Metab. 2018;20:1361-6. https://doi.org/10.1111/dom.13229.

82. Verma S, Mazer CD, Yan AT, et al. Effect of Empagliflozin on Left Ventricular Mass in Patients with Type 2 Diabetes and Coronary Artery Disease: The EMPA-HEART CardioLink-6 Randomized Clinical Trial. Circulation. 2019;140:1693-702. https://doi.org/10. 1161/CIRCULATIONAHA.119.042375.

83. Soga F, Tanaka H, Tatsumi K, et al. Impact of dapagliflozin on left ventricular diastolic function of patients with type 2 diabetic mellitus with chronic heart failure. Cardiovasc Diabetol. 2018;17: 132. https://doi.org/10.1186/s12933-018-0775-z.
84. Jensen J, Omar M, Kistorp C, et al. Empagliflozin in heart failure patients with reduced ejection fraction: a randomized clinical trial (Empire HF). Trials. 2019;20:374. https://doi.org/10.1186/s13063019-3474-5

85. Mordi NA, Mordi IR, Singh JS, et al. Renal and Cardiovascular Effects of sodium-glucose cotransporter 2 (SGLT2) inhibition in combination with loop Diuretics in diabetic patients with Chronic Heart Failure (RECEDE-CHF): protocol for a randomised controlled double-blind cross-over trial. BMJ Open. 2017;7:e018097. https://doi.org/10.1136/bmjopen-2017-018097.

86. Singh JSS, Fathi A, Vickneson K, et al. Research into the effect Of SGLT2 inhibition on left ventricular remodelling in patients with heart failure and diabetes mellitus (REFORM) trial rationale and design. Cardiovasc Diabetol. 2016;15:97. https://doi.org/10.1186/ s12933-016-0419-0.

87. Åkerblom A, Oldgren J, Latva-Rasku A, et al. Effects of DAPAgliflozin on CARDiac substrate uptake, myocardial efficiency, and myocardial contractile work in type 2 diabetes patients-a description of the DAPACARD study. Ups J Med Sci. 2019;124: 59-64. https://doi.org/10.1080/03009734.2018.1515281.

88. Abraham WT, Ponikowski P, Brueckmann M, et al. Rationale and design of the EMPERIAL-Preserved and EMPERIAL-Reduced trials of empagliflozin in patients with chronic heart failure. Eur J Heart Fail. 2019;21:932-42. https://doi.org/10.1002/ejhf.1486.

89. Nassif ME, Windsor S, Tang F, et al. Dapagliflozin Effects on Biomarkers, Symptoms, and Functional Status in Patients With Heart Failure With Reduced Ejection Fraction: The DEFINE-HF Trial. Circulation. 2019;140:1463-76. https://doi.org/10.1161/ CIRCULATIONAHA.119.042929.

90. Vardeny O, Vaduganathan M. Practical guide to prescribing sodium-glucose cotransporter 2 inhibitors for cardiologists. JACC Hear Fail. 2019;7:169-72. https://doi.org/10.1016/j.jchf.2018.11.013.

91. Seferovic PM, Ponikowski P, Anker SD, et al. Clinical practice update on heart failure 2019: pharmacotherapy, procedures, devices and patient management. An expert consensus meeting report of the Heart Failure Association of the European Society of Cardiology. Eur J Heart Fail. 2019;21:1169-86. https://doi.org/10.1002/ejhf. 1531.

92. Wanner C, Inzucchi SE, Zinman B. Empagliflozin and progression of kidney disease in type 2 diabetes. N Engl J Med. 2016;375: 1801-2. https://doi.org/10.1056/NEJMc1611290.

93. Mullens W, Damman K, Harjola V-P, et al. The use of diuretics in heart failure with congestion - a position statement from the Heart Failure Association of the European Society of Cardiology. Eur J Heart Fail. 2019;21:137-55. https://doi.org/10.1002/ejhf.1369.

94. Cherney DZI, Udell JA. Use of sodium glucose cotransporter 2 inhibitors in the hands of cardiologists: with great power comes great responsibility. Circulation. 2016;134(24):1915-7. https://doi. org/10.1161/CIRCULATIONAHA.116.024764.

95. Dunlay SM, Givertz MM, Aguilar D, et al. Type 2 diabetes mellitus and heart failure: A scientific statement from the American Heart Association and the heart failure society of America. J Card Fail. 2019;25:584-619. https://doi.org/10.1016/j.cardfail.2019.05.007.

96. Hammond DA, Smith MN, Lee KC, et al. Acute decompensated heart failure. J Intensive Care Med. 2018;33:456-66. https://doi. org/10.1177/0885066616669494.

97. Damman K, Beusekamp JC, Boorsma EM, et al. Randomized, double-blind, placebo-controlled, multicentre pilot study on the effects of empagliflozin on clinical outcomes in patients with acute decompensated heart failure (EMPA-RESPONSE-AHF). Eur J Heart Fail. 2020. https://doi.org/10.1002/ejhf.1713.

Publisher's Note Springer Nature remains neutral with regard to jurisdictional claims in published maps and institutional affiliations. 